\title{
A GESTÃO EDUCACIONAL E A QUALIDADE EDUCACIONAL NA LDB: MEDIDAS E PADRÕES (NEM SEMPRE) CONGRUENTES
}

\author{
LA GESTIÓN EDUCATIVA Y LA CALIDAD EDUCATIVA EN LA LDB: \\ MEDIDAS Y ESTÁNDARES (NO SIEMPRE) CONGRUENTES
}

\author{
EDUCATIONAL MANAGEMENT AND EDUCATIONAL QUALITY IN THE \\ “LDB”: MEASURES AND STANDARDS (NOT ALWAYS) CONGRUENT
}

Pablo Silva Machado Bispo dos SANTOS ${ }^{1}$

RESUMO: O presente trabalho visa a discutir como a noção de Qualidade (em especial a que se refere à Qualidade Educacional) é apresentada na Constituição Federal e na LDB. O objetivo, para além de mera análise exegética é apresentar como esta ideia basilar (a Qualidade) dá ensejo no texto da Lei a interpretações incongruentes e/ou contraditórias no que tange a sua implementação no âmbito das Políticas Educacionais voltadas para a Gestão Educacional no Brasil.

PALAVRAS-CHAVE: Educação. Gestão educacional. Qualidade educacional.

RESUMEN: El presente trabajo pretende discutir cómo la noción de Calidad (en especial la que se refiere a la Calidad Educativa) es presentada en la Constitución Federal y en la LDB. El objetivo, además de mera análisis exegético es presentar como esta idea basilar (la Calidad) da lugar en el texto de la Ley a interpretaciones incongruentes y / o contradictorias en lo que se refiere a su implementación en el ámbito de las Políticas Educativas dirigidas a la Gestión Educativa en Brasil.

PALABRAS CLAVE: Educación. Gestión educativa. Calidad educativa.

ABSTRACT: The present work aims at discussing how the notion of Quality (especially in what refers to Educational Quality) is presented in the Federal Constitution and LDB. The objective, besides mere exegetical analysis, is to present how this basic idea (the Quality) gives rise in the text of the Law to inconsistent and / or contradictory interpretations regarding its implementation in the scope of Educational Policies geared to Educational Management in Brazil.

KEYWORDS: Education. Educational management. Educational quality.

${ }^{1}$ Universidade Federal Fluminense (Uff), Santo Antônio de Pádua - RJ - Brasil. Professor Associado do INFES-UFF e professor do Programa de Pós-Graduação em Educação da UFF. E-mail: psmbsantos@gmail.com.

RPGE - Revista on line de Política e Gestão Educacional, Araraquara, v. 22, n. esp.1, p. 209-222, mar., 2018. 


\title{
Introdução
}

\begin{abstract}
Apesar das grandes transformações e do progresso científico e tecnológico, as injustiças sociais continuam aumentando. Todavia, é possível para o ser humano viver em um mundo em que não haja exclusão, em que haja respeito e promoção da dignidade humana. E, para que isso aconteça, necessitamos de educação de qualidade, já que, por seu intermédio, poderá haver a defesa respeitosa dos seres humanos, com a utilização de uma prática educativa concreta ética e consciente, a fim de que haja igualdade e justiça social (MENDES, 2010, p. 69).
\end{abstract}

A qualidade e uma das categorias fundamentadoras do juízo humano. Do mesmo modo que a quantidade permite aferir a unidade ou a multiplicidade relativa a determinado elemento, a qualidade é a faculdade humana que torna possível a aferição de modificações intrínsecas ao elemento do real sobre o qual incide, além de possibilitar que este seja comparado com elementos semelhantes em condições similares.

Em matéria de educação, a qualidade em suas múltiplas variações encontra sempre alguma vinculação com os atos de aprender e ensinar, de modo que, muito embora possam ser muitos os parâmetros de aferição da qualidade, ainda assim, estes parâmetros estão (ou deveriam estar) ligados aos já mencionados atos. Assim, é possível enquadrar a qualidade educacional nos seguintes âmbitos e indicadores: a) qualidade da aprendizagem (relativo ao quanto os professores, escolas e sistemas de ensino são capazes de ensinar); b) qualidade da gestão/administração (referente ao quanto os professores e gestores dos sistemas de ensino conseguem gerenciar com eficiência, eficácia e efetividade os recursos disponíveis para subsidiar a atividade-fim do ensino em seu contexto); c) qualidade social (relativo ao modo como os elementos das comunidades educacionais nos níveis das salas de aula, instituições e sistemas de ensino participam das decisões e das ações realizadas nestes âmbitos).

Após esta digressão seguiremos rumo a uma análise de como a temática da Qualidade Educacional tem sido concretizada no âmbito da Legislação Educacional brasileira, com ênfase na Constituição Federal de 1988 e na Lei de Diretrizes e Bases da Educação Nacional (Lei 9.394/96). Para tanto foram analisados os referidos diplomas legais considerando as modificações relacionadas à temática da Qualidade Educacional no período concernente às duas primeiras décadas após a promulgação da Lei 9.394/96.

\section{A qualidade educacional na Constituição Federal de 1988 (CF/88) e na Lei 9.394/96} (LDB): um início de conversa

RPGE - Revista on line de Política e Gestão Educacional, Araraquara, v. 22, n. esp.1, p. 209-222, mar., 2018. 
Nesta seção do trabalho são discutidas as formas assumidas pela Qualidade Educacional no âmbito de nosso ordenamento jurídico, em especial no que diz respeito aos aspectos estruturantes e matriciais do que alude a redes e sistemas de ensino. Assim, os dois pilares do ordenamento jurídico-político da educação brasileira (SANTOS, 2014), quais sejam: a CF/88 e a LDB são abordados quanto a esta temática.

\section{A qualidade educacional na CF/88}

A temática da Qualidade Educacional surge na CF/88 na medida em que esta é inserida como um dos elementos constitutivos do Direito à Educação, integrando os Princípios da Educação Nacional, tais como estabelecidos no Art. 206, especialmente no inciso VII, cuja redação é a seguinte: "VII - Garantia de Padrão de Qualidade (BRASIL, 1988)". A questão que se coloca então é a seguinte: em que se baseia este padrão de qualidade? E como decorrência desta questão temos ainda a seguinte: qual noção de qualidade embasa os Princípios da Educação Nacional presentes na CF/88.

Ainda na Carta Magna se verifica a existência de algumas "pistas" que podem auxiliar na resposta a estas indagações. Vamos então rumo ao Art. 208, relativo ao dever do Estado para com a Educação e cujos incisos que o compõem apresentam a seguinte redação:

I - educação básica obrigatória e gratuita dos 4 (quatro) aos 17 (dezessete) anos de idade, assegurada inclusive sua oferta gratuita para todos os que a ela não tiveram acesso na idade própria; (Redação dada pela Emenda Constitucional $\mathrm{n}^{\circ} 59$, de 2009) (Vide Emenda Constitucional $\mathrm{n}^{\circ}$ 59, de 2009); II - progressiva universalização do ensino médio gratuito; (Redação dada pela Emenda Constitucional $n^{\circ}$ 14, de 1996); III - atendimento educacional especializado aos portadores de deficiência, preferencialmente na rede regular de ensino; IV - educação infantil, em creche e pré-escola, às crianças até 5 (cinco) anos de idade; (Redação dada pela Emenda Constitucional $n^{\circ}$ 53, de 2006); V - acesso aos níveis mais elevados do ensino, da pesquisa e da criação artística, segundo a capacidade de cada um; VI oferta de ensino noturno regular, adequado às condições do educando; VII - atendimento ao educando, em todas as etapas da educação básica, por meio de programas suplementares de material didático escolar, transporte, alimentação e assistência à saúde. (Redação dada pela Emenda Constitucional no 59, de 2009).

Especial atenção deve ser dada aos incisos III, V, VI e VII do Art. 208, os quais tratam respectivamente dos seguintes temas: a) Educação Inclusiva e Atendimento

RPGE - Revista on line de Política e Gestão Educacional, Araraquara, v. 22, n. esp.1, p. 209-222, mar., 2018. 
Educacional Especializado (AEE); b) Capacidade individual e acesso à Educação; c) Garantia de Ensino Noturno; d) Atendimento suplementar à Educação Básica.

No que diz respeito ao primeiro dos temas abordados pelo Art. 208, a qualidade surge associada de modo indireto a partir da garantia de atendimento especializado (quando necessário) aos portadores de deficiência. Nesse sentido, está presente o princípio da equidade, ou seja, a garantia de um tratamento diferenciado a quem possui necessidades diferentes. Assim, uma das pistas relativas à noção de Qualidade Educacional presentes na $\mathrm{CF} / 88$ é o princípio da equidade, colocado aqui em uma perspectiva de unidade na diversidade, ou seja, sem que o princípio da garantia fundamental ao Direito à Educação (tal como disposto no Art. 205, o qual indica que a Educação é Direito de Todos) há a previsão de AEE .

Em relação ao (polêmico) tema da capacidade individual, há que salientar dois elementos: 1) a redação do inciso é por demais ampla e vaga pois não há nem a definição de quais são estes níveis mais altos e nem tampouco como a capacidade individual poderia ser aferida; 2) este inciso introduz de modo sub-reptício a noção de meritocracia, associada muito mais à capacidade individual do que às condições de escolarização existentes na sociedade. Com base nestes elementos mais uma pista pode ser depreendida: a Qualidade Educacional na $\mathrm{CF} / 88$ tem a ver com uma visão individualista no que se refere ao acesso ao ensino, pesquisa e criação artística, especialmente no tocante aos níveis superiores dos sistemas de ensino.

No que tange à garantia de ensino noturno adequado às condições do educando é possível perceber mais uma vez o princípio da equidade vinculando de modo indireto a Qualidade Educacional ao dever do Estado para com a Educação, na medida em que entende que deve ser garantido o ensino noturno de acordo com as condições do educando, especialmente naquilo que alude aos que não puderam cursar na idade adequada a escola regular, ou seja, não pode simplesmente ser ofertado o ensino noturno sem que este se adapte a tais condições especiais, havendo novamente então uma menção velada à equidade, posicionada porém no eixo dos tempos escolares, que neste caso se tornam diferentes. Face ao exposto a pista que surge neste inciso diz respeito a uma noção de qualidade que aponta para uma flexibilização dos tempos escolares, e que tem a ver com a dimensão pedagógica da Qualidade Educacional aplicada a partir do princípio da equidade.

A suplementação de condições de acesso a material didático, transporte escolar e alimentação no âmbito da Educação Básica indica que outra das pistas quanto a 
qualidade educacional diz respeito à infraestrutura administrativa referente ao suporte à Educação Básica, o qual (conforme se apresenta na LDB) possui ativa participação do Governo Federal em sua efetivação.

A menção ao padrão mínimo de qualidade presente no primeiro parágrafo do Art. 211 indica que este será um dos eixos no que se refere à colaboração entre os entes federados. Assim, esta dimensão administrativa da qualidade surge na CF/88 pois há (de modo subjacente) a premissa de que tal efetivação pressupõe uma colaboração entre os entes federados (tal como se encontra exposto no Art. 211 que regulamenta esta matéria).

Após esta breve análise da matéria educacional da $\mathrm{CF} / 88$ torna-se necessário confrontar estas "pistas" com o que fora regulamentado pela LDB.

\section{A qualidade educacional na LDB}

A LDB, sem sombra de dúvida não pode ser reputada como uma lei comum. Apesar de não ser promulgada com o status cabível a uma Lei Complementar, ainda assim ela é o elemento jurídico (mas também político) norteador de um importante segmento dos direitos e garantias fundamentais do indivíduo: a Educação. Devido a suas características matriciais (é uma Lei que estabelece diretrizes e bases) vem a ser elemento fulcral do ordenamento jurídico-político brasileiro no que tange à Educação. Assim sendo, uma de suas funções primordiais é a de detalhar e ampliar o que se encontra disposto na CF/88 no que tange a esta área do Estado. Deste modo, sua função está para além do texto legal, vindo a se consubstanciar na essência das Políticas Públicas Regulatórias, Distributivas e Redistributivas em matéria de Educação (FREY, 2000). Tendo em vista focalizar o tema tratado neste artigo, vamos então ao que se encontra disposto no texto da Lei.

No que tange ao tema da qualidade, exame assaz perfunctório permite perceber que há dez menções diretas à qualidade no diploma legal. As referidas menções se encontram nos artigos: 3, 4, 7, 9, 47, 70, 71, 74, 75. É possível dividir em dois grupos temáticos as referidas menções. A seguir os mesmos serão detalhados.

\section{A qualidade educacional e a organização da Educação Básica na LDB}

RPGE - Revista on line de Política e Gestão Educacional, Araraquara, v. 22, n. esp.1, p. 209-222, mar., 2018. 
O primeiro grupo de artigos trata da qualidade no que se refere à Organização da Educação Nacional (em especial no que se refere à Educação Básica) e diz respeito (ao menos em parte) aos artigos 3,4,7, 9 e 47.

Os artigos 3 e 4 retomam o tema da qualidade reafirmando os Princípios da Educação Nacional presentes no Art. 206 da CF/88. A parte do artigo 3 que trata da qualidade é a seguinte: [...]O ensino será ministrado com base nos seguintes princípios [...] IX - Garantia de Padrão de Qualidade (BRASIL, 1996)”. Já o trecho do artigo 4 relativo a esta temática corresponde a:

O dever do Estado com educação escolar pública será efetivado mediante a garantia de [...] IX $\neg$ padrões mínimos de qualidade de ensino, definidos como a variedade e quantidade mínimas, por aluno, de insumos indispensáveis ao desenvolvimento do processo de ensino-aprendizagem (BRASIL, 1996).

Enquanto no artigo 3 temos uma definição por demais ampla no que diz respeito à garantia de Padrão de Qualidade (Como se garante tal padrão? Em que este se consubstancia?), o artigo 4 fixa indicadores quantitativos e quantitativos mínimos, os quais têm na figura do aluno o eixo referencial quanto aos insumos indispensáveis ao ensino-aprendizagem, sem, no entanto, definir quais são tais insumos.

O artigo 7, por sua vez faz menção à necessária avaliação de qualidade pelo poder público a que devem se submeter as instituições educacionais privadas, e o trecho que menciona explicitamente este tema é o seguinte: $\mathrm{O}$ ensino é livre à iniciativa privada, atendidas as seguintes condições[...] II $\neg$ - autorização de funcionamento e avaliação de qualidade pelo Poder Público (BRASIL, 1996). Temos então neste artigo a noção de que caberá ao Estado aferir a qualidade, condicionando o funcionamento das instituições privadas ao atendimento dos padrões por ele definidos (em qualquer das esferas dos entes federados).

Já o art. 9 alude a padrões mínimos de qualidade no que se refere às atribuições da União. Eis o trecho referente à temática:

A União incumbir-se-á de [...] VI - assegurar processo nacional de avaliação do rendimento escolar no ensino fundamental, médio e superior, em colaboração com os sistemas de ensino, objetivando a definição de prioridades e a melhoria da qualidade do ensino (BRASIL, 1996).

RPGE - Revista on line de Política e Gestão Educacional, Araraquara, v. 22, n. esp.1, p. 209-222, mar., 2018. 
Neste excerto mostra-se patente o fato de que a União é o ente federado preponderante na definição de prioridades e diretrizes no que tange a qualidade de ensino, em que pese o fato de que a mesma igualmente conduzirá processo nacional de avaliação do rendimento escolar em todos os níveis de ensino. Assim, no que se refere à Organização da Educação no Brasil há uma centralidade administrativa e pedagógica dos processos avaliativos em larga escala, os quais vêm a compor um eixo de estruturação pedagógica e administrativa das redes e sistemas de ensino (CURY, 1998), ensejando uma centralização crescente no que diz respeito à Gestão Educacional Pública.

$\mathrm{O}$ arremate das questões relativas à Organização da Educação Nacional e que tangenciam a temática da Qualidade Educacional se dá no art. 47, relativo à Educação Superior, neste artigo temos a passagem que se segue e ilustra o que se pretende demonstrar:

$\S 4^{\circ}$ As instituições de educação superior oferecerão, no período noturno, cursos de graduação nos mesmos padrões de qualidade mantidos no período diurno, sendo obrigatória a oferta noturna nas instituições públicas, garantida a necessária previsão orçamentária (BRASIL, 1996).

Há neste parágrafo uma menção velada à questão da equidade, tal como fora feita na $\mathrm{CF} / 88$ em relação à garantia de qualidade para os educandos de cursos noturnos. Há que se observar, porém, que mesmo a Educação Superior estando fora do escopo da escolaridade obrigatória, ainda assim, a padronização pedagógica e administrativa presente na LDB no que se refere à Qualidade faz com que sejam levados a termo (do ponto de vista legal) os mesmos pressupostos que garantem ao aluno trabalhador o acesso a padrões similares de ensino.

Após este exame dos artigos relativos à Organização da Educação no Brasil na LDB em sua relação com a Qualidade Educacional, constata-se que a padronização efetuada nestes artigos incide (prioritariamente) sobre a dimensão administrativa e a dimensão pedagógica. Ainda que as questões referentes a infraestrutura estejam presentes, ainda assim estas surgem de modo indireto (como, por exemplo, a referência a insumos que garantam condições mínimas de ensino-aprendizagem na Educação Básica). Vejamos a seguir como estas questões surgem na próxima seção deste trabalho. 


\title{
A qualidade educacional na LDB e as questões da infraestrutura: o financiamento educacional em foco
}

Em uma sociedade capitalista a infraestrutura física de qualquer instituição se torna indissociável dos recursos financeiros que precedem à sua construção e manutenção. Assim sendo, o financiamento educacional ganha relevo quando o assunto diz respeito à infraestrutura física. Entendendo que as questões relativas à qualidade não podem prescindir de uma base concreta (sobretudo no que diz respeito à Educação Escolar), o financiamento é fator preponderante pois a partir dele há a provisão de recursos de custeio (materiais de consumo, sejam eles referentes à equipagem pedagógica, sejam relativos ao custo operacional das instituições), capital (relativos a instalações e bens móveis permanentes pertencentes à administração pública) e de pessoal ( o pagamento de salários e benefícios de todos os trabalhadores envolvidos na dinâmica educacional dessas instituições, direta ou indiretamente).

Após este breve (porém necessário) introito, vamos em direção aos artigos da LDB que se referem à temática do Financiamento Educacional, cuja relação com a Qualidade Educacional se dá a partir da vinculação indissociável com a dimensão da infraestrutura. Os referidos artigos são os seguintes: 70, 71, 73, 74 e 75.

De modo a iniciar este exame da matéria proposta (a relação entre Qualidade Educacional e Financiamento na LDB), eis a redação do art. 70 da LDB:

\begin{abstract}
Art. 70. Considerar-se-ão como de manutenção e desenvolvimento do ensino as despesas realizadas com vistas à consecução dos objetivos básicos das instituições educacionais de todos os níveis, compreendendo as que se destinam a: I - remuneração e aperfeiçoamento do pessoal docente e demais profissionais da educação; II - aquisição, manutenção, construção e conservação de instalações e equipamentos necessários ao ensino; III - uso e manutenção de bens e serviços vinculados ao ensino; IV levantamentos estatísticos, estudos e pesquisas visando precipuamente ao aprimoramento da qualidade e à expansão do ensino; V - realização de atividades-meio necessárias ao funcionamento dos sistemas de ensino; VI - concessão de bolsas de estudo a alunos de escolas públicas e privadas; VII - amortização e custeio de operações de crédito destinadas a atender ao disposto nos incisos deste artigo; VIII aquisição de material didático-escolar e manutenção de programas de transporte escolar.
\end{abstract}

Conforme se percebe, o artigo diz respeito à definição das despesas de manutenção e desenvolvimento do ensino. O ensino como componente indispensável da Educação é elemento indispensável da dimensão pedagógica da Qualidade Educacional

RPGE - Revista on line de Política e Gestão Educacional, Araraquara, v. 22, n. esp.1, p. 209-222, mar., 2018. 
mas a ela não se circunscreve. É precisamente por isso que a LDB traz avanços ao definir quais são as despesas de manutenção e desenvolvimento do ensino passíveis de financiamento público no âmbito da responsabilidade constitucional da União (nunca menos de $18 \%$ de receita resultante de impostos). Eis então a necessária vinculação entre a dimensão pedagógica e a dimensão da infraestrutura no âmbito da LDB, que leva então ao entendimento de que abaixo de um patamar mínimo de investimentos não há a necessária qualidade do ensino. Especial atenção deve ser dada aos incisos que vão de IV a VI, pois introduz a dinâmica da Pesquisa Educacional como elemento do planejamento das referidas despesas (mas não somente estas), bem como delimita as atividades-meio que podem ser financiadas (aquelas vitais aos sistemas de ensino), bem como compreende que em alguns casos torna-se necessário inclusive o recurso a bolsas de estudo como forma de subsidiar esta melhoria qualitativa.

Ainda sobre o que fora exposto no artigo 70, há uma elemento que diz respeito ao financiamento público e que merece de nossa parte um exame rigoroso: o caput do artigo faz referência às despesas de manutenção e desenvolvimento do ensino das instituições educacionais, sem que sejam, no entanto, discriminadas as instituições públicas ou privadas de ensino. Esta é uma discussão absolutamente central pois na medida em que se abre a possibilidade de haver uma interpretação de que os recursos públicos (especialmente os $18 \%$ previstos para a União) podem ser utilizados para financiar instituições educacionais privadas, sem sombra de dúvida a Qualidade Educacional das instituições educacionais públicas poderia sofrer um decréscimo devido à existência de menos recursos de infraestrutura para o seu financiamento.

Em relação ao artigo 71, há que se registrar que o mesmo traz uma redação "negativa", indicando quais são as despesas que não podem ser incluídas no rol das despesas com manutenção e desenvolvimento do ensino. Merece realce o fato de que a Qualidade Educacional se mostra, a partir deste procedimento legal, adstrita às despesas de manutenção e desenvolvimento do ensino, o que se reforça com os artigos 72 e 73 da LDB os quais indicam que as referidas despesas devem ser publicadas nas prestações de contas anuais e no Diário Oficial da União (art. 72), bem como, devem ser prioritariamente examinadas com fulcro nos Art. $212 \mathrm{CF}$ e Art 60 do Ato das Disposições Constitucionais Transitórias (art. 73). Deve ainda ser salientado que nesta seção da LDB que trata do Financiamento Educacional (e que, conforme visto, se vincula à questão da Qualidade Educacional) os artigos 72 e 73 realizam uma espécie de “cobertura” jurídica (mas também política) de modo a vincular os orçamentos públicos a 
investimentos focalizados em educação. Não é demais recordar que um dos Princípios da Administração Pública é o princípio da publicidade, o qual não se dissocia do princípio da eficiência. Assim sendo, não há que se pensar em eficiência na aplicação de recursos financeiros sem a normatização de seu investimento e sem o necessário controle social de suas finalidades. Os artigos 72 e 73 da LDB visam a realizar esta junção entre os pressupostos básicos do Direito Administrativo (presentes com ênfase no art. 37 da CF) à questão da Qualidade Educacional.

Se nos artigos 72 e 73 da LDB vimos a preparação de uma "cobertura jurídica" no tocante à questão da Qualidade Educacional, o artigo 74 por sua vez possui uma redação que define atribuições à União e aos demais entes federados no que compete à delimitação e manutenção de um indicador paramétrico para as inversões orçamentárias realizadas com este fim. A redação do referido artigo é a seguinte: “Art. 74. A União, em colaboração com os Estados, o Distrito Federal e os Municípios, estabelecerá padrão mínimo de oportunidades educacionais para o ensino fundamental, baseado no cálculo do custo mínimo por aluno, capaz de assegurar ensino de qualidade".

O mínimo de oportunidades educacionais definido de modo conjunto entre os entes federativos (no que tange ao Ensino Fundamental) se liga à equidade, um dos princípios já discutidos e que tem a ver com a noção de Qualidade Educacional trazida pela LDB. O estabelecimento de um custo mínimo por aluno sem dúvida alguma representou um avanço, na medida em que permite às redes de ensino estimar seus gastos, bem como à administração pública direcionar recursos relativos ao ensino, de modo a permitir que existam condições mínimas de infraestrutura no acesso ao Ensino Fundamental (ainda que se possa argumentar que tal cobertura devesse ser ampliada em direção a toda a Educação Básica, não há como negar que este é um avanço importante).

Há que ser observado, no entanto, um elemento importante: o que caracteriza um ensino de qualidade? Como a LDB não fornece essa resposta abre-se margem de discricionariedade para os demais entes federativos construírem suas visões acerca desta noção. Por um lado, isso expressa a autonomia, reafirmada como princípio, por outro, demonstra a existência de um movimento contrário ao restante da regulamentação trazida pelos artigos que vão de 70 a 73 pois estes estavam justamente colocando elementos jurídico-políticos capazes de dar um norte quanto ao que seria a Qualidade Educacional no que se refere a questões da dimensão da infraestrutura dos sistemas de ensino. Do ponto de vista prático isto redunda em uma contradição que traz obstáculos na aplicação dos recursos supracitados.

RPGE - Revista on line de Política e Gestão Educacional, Araraquara, v. 22, n. esp.1, p. 209-222, mar., 2018. 
Por último, mas nem por isso menos importante, no artigo 75 da LDB há a menção à ação redistributiva e supletiva da União. O artigo possui a seguinte redação:

\begin{abstract}
Art. 75. A ação supletiva e redistributiva da União e dos Estados será exercida de modo a corrigir, progressivamente, as disparidades de acesso e garantir o padrão mínimo de qualidade de ensino. $\S 1^{\circ} \mathrm{A}$ ação a que se refere este artigo obedecerá a fórmula de domínio público que inclua a capacidade de atendimento e a medida do esforço fiscal do respectivo Estado, do Distrito Federal ou do Município em favor da manutenção e do desenvolvimento do ensino. $\S 2^{\circ}$ A capacidade de atendimento de cada governo será definida pela razão entre os recursos de uso constitucionalmente obrigatório na manutenção e desenvolvimento do ensino e o custo anual do aluno, relativo ao padrão mínimo de qualidade. $\S 3^{\circ}$ Com base nos critérios estabelecidos nos $\S \S 1^{\circ}$ e $2^{\circ}$, a União poderá fazer a transferência direta de recursos a cada estabelecimento de ensino, considerado o número de alunos que efetivamente freqüentam a escola. $\S 4^{\circ} \mathrm{A}$ ação supletiva e redistributiva não poderá ser exercida em favor do Distrito Federal, dos Estados e dos Municípios se estes oferecerem vagas, na área de ensino de sua responsabilidade, conforme o inciso VI do art. 10 e o inciso $\mathrm{V}$ do art. 11 desta Lei, em número inferior à sua capacidade de atendimento.
\end{abstract}

O padrão mínimo de qualidade de ensino a que se refere o artigo corresponde ao índice de Desenvolvimento da Educação Básica (IDEB) utilizado como indicador prioritário para a medição da eficiência do rendimento escolar das redes de ensino. Esta tendência no sentido de tomar aferição como sinônimo de avaliação merece ser comentada pois um dos desdobramentos que mais se fizeram notar após a promulgação da LDB foi o predomínio de ações e programas educacionais que visavam a ampliar o controle sobre os sistemas de ensino por intermédio da avaliação, baseando, porém, seus indicadores na noção de que aferição é sinônimo de avaliação.

Assim sendo, o artigo 75 ratifica a visão de avaliação como sinônimo de aferição de scores, conectando esta dimensão pedagógica aos mecanismos envolvidos nos repasses de recursos para a administração pública. A esse respeito, a leitura dos parágrafos subsequentes ao caput do artigo traz o entendimento de quais são estas condições e normas: a) existência de uma fórmula de domínio público que permita acompanhar o "esforço fiscal" do ente federado (parágrafo primeiro); b) estimativa da capacidade de atendimento de cada governo com base na comparação entre o indicador do custo por aluno e o investimento realizado nas referidas despesas de manutenção do ensino (parágrafo segundo); c) condicionamento da ação supletiva e redistributiva da União ao oferecimento de vagas pelos entes federados de acordo com a sua capacidade

RPGE - Revista on line de Política e Gestão Educacional, Araraquara, v. 22, n. esp.1, p. 209-222, mar., 2018. 
de atendimento (parágrafo quarto). Ao serem analisadas estas condições, há que se notar que a capacidade de atendimento e o custo por aluno são os principais indicadores de qualidade no que compete ao financiamento educacional, regulamentado em nível federal e cuja matriz se espalha em direção aos entes federados.

À guisa de conclusão, há que levar em conta o fato de que, do mesmo modo que a $\mathrm{LDB}$ e a $\mathrm{CF} / 88$ trazem alguns princípios (como a equidade) para as dimensões Pedagógica e administrativa, nas partes que tratam da Organização da Educação no Brasil, os artigos que vão de 70 a 75 na LDB (e que tratam a questão do financiamento) realizam uma junção entre a dimensão da infraestrutura (no que diz respeito à Qualidade Educacional) aos princípios da legalidade, publicidade e eficiência (tal como visto no Art. 37 da CF/88) enquadrando assim a Qualidade Educacional a parâmetros e indicadores que surgem no âmbito das normas gerais da Administração Pública (como, por exemplo as fórmulas para o cálculo da capacidade de atendimento educacional do governo a que são repassados os recursos da União relativos à manutenção e desenvolvimento do ensino). Deste modo, ao longo dos vinte anos de promulgação da LDB assistimos ao aprofundamento de uma visão de qualidade que coloca em oposição a autonomia dos sistemas de ensino e padrões únicos de aferição de desempenho (e que são apresentados como sinônimos de indicadores de qualidade, diga-se de passagem).

\section{Considerações finais}

A preocupação central deste trabalho foi a de realizar uma discussão referente ao momento histórico compreendido nas duas décadas de promulgação da LDB, cabe assinalar, porém, que mais do que uma análise exegética ou puramente histórica, procurou-se fazer uma correlação entre o texto da Lei (e suas mudanças) e alguns elementos integrantes da Política Educacional e que dizem respeito a ações, planos e programas voltados para a dimensão da qualidade.

Conforme se percebeu, a grande contradição que se coloca é; a ênfase em indicadores centrais (e, diria, de crescente integração sistêmica) de medição de "scores" paramétricos se contrapõe à autonomia dos sistemas e redes de ensino (prevista igualmente na LDB), bem como se choca de maneira frontal com a necessária pluralidade (de indicadores, objetivos e métodos) implicados na dinâmica da avaliação educacional em cenários de grande complexidade tais como o que se configura no

RPGE - Revista on line de Política e Gestão Educacional, Araraquara, v. 22, n. esp.1, p. 209-222, mar., 2018. 
Sistema Nacional de Avaliação nos segmentos da Educação Básica e da Educação Superior.

Deste modo, cabe então destacar o fato de que, devido a sua estrutura matricial no que tange ao ordenamento jurídico-político brasileiro, a LDB ensejou a construção de uma estrutura subjacente de padronização de indicadores, métodos e técnicas de aferição de desempenho escolar (nas dimensões da Avaliação da Aprendizagem e da Avaliação Institucional) com tendência de uniformidade e que possui em seus elementos constitutivos a ênfase na mensuração dos já referidos indicadores em detrimento de processos "compreensivos" de avaliação processual, os quais, por suas características qualitativas possuem um refinamento capaz de (por exemplo) realizar ponderações dos scores com base no contexto social, cultural e econômico das populações avaliadas, o que viria a relativizar a medida de padrão único.

Concluindo, cabe afirmar que ao longo dos 20 anos de promulgação da LDB a Qualidade Educacional tem sido cada vez mais entendida como sinônimo de medidas educacionais e não de compreensão dos processos educacionais, de modo que é necessário questionar por quanto tempo ainda teremos um desprezo por métodos avaliativos processuais, inclusivos e calcados no princípio da equidade e que viriam justamente a tornar mais ampla e plural a qualidade educacional na medida em que a centralidade assumida pela dimensão avaliativa se reveste de um caráter mais dinâmico e completo.

\section{REFERÊNCIAS}

BRASIL. Constituição da República Federativa do Brasil de 1988. Brasília, Secretaria de Assuntos Jurídicos da Casa Civil. Disponível em: <http://www.planalto.gov.br/ccivil_03/constituicao/constituicaocompilado.htm>. Acesso em: 08 mar. 2017.

BRASIL. Lei 9.394 de 20 de dezembro de 1996. Brasília, Secretaria de Assuntos Jurídicos da Casa Civil. Disponível em:

<http://www.planalto.gov.br/ccivil_03/leis/L9394.htm>. Acesso em: 09 mar. 2017.

CURY, Carlos Roberto Jamil. Perspectivas da Educação Brasileira e a LDB. Revista do COGEIME, n. 12, jun., 1998.

FREY, Klaus. Políticas públicas: um debate conceitual e reflexões referentes à prática da análise de políticas públicas no Brasil. Planejamento e Políticas Públicas, n. 21, jun., 2000, p. 211-261.

RPGE - Revista on line de Política e Gestão Educacional, Araraquara, v. 22, n. esp.1, p. 209-222, mar., 2018. 
LUCKESI, Cipriano. Avaliação da aprendizagem. São Paulo, Cortez: 2000.

MENDES, Maria Socorro dos Santos. O ideário da qualidade de ensino na escola pública: uma leitura crítica sob a ótica da Psicologia escolar. Psicol. Ensino \& Form., Brasília, v. 1, n. 2, p.61-71, 2010.

SANTOS, Pablo Silva Machado Bispo dos. Guia prático da política educacional no Brasil: ações, planos, programas e impactos. São Paulo, CENGAGE: 2014.

SANTOS, Pablo Silva Machado Bispo dos. A Constituição Federal e a Lei de Diretrizes e Bases da Educação Nacional como matrizes estruturantes do campo político brasileiro: analisando o campo do poder e a refração política no âmbito da gestão democrática. Periferias, v. 6, n. 2, jul-dez, 2015, Rio de Janeiro.

TRIGUEIRO MENDES, Durmeval. O planejamento educacional no Brasil. Rio de Janeiro, EDUERJ: 2000.

\section{Como referenciar este artigo}

SANTOS, Pablo Silva Machado Bispo dos. A gestão educacional e a qualidade educacional na LDB: medidas e padrões (nem sempre) congruentes. Revista on line de Política e Gestão Educacional, Araraquara, v. 22, n. esp.1, p. 209-222, mar., 2018. EISSN:1519-9029.

Submetido em: 04/10/2017

Aprovado em: 14/12/2017 